\title{
Correction to: Can Cosmetics' Advertisements Be An Indicator of Different Perceptions of Beauty Amongst Countries?
}

\author{
Georgia Alexandra Spyropoulou ${ }^{1} \cdot$ Leonidas Pavlidis $^{1} \cdot$ Steve Herrmann $^{2} \cdot$ \\ Antonis Tsimponis ${ }^{1} \cdot$ Periclis Foroglou $^{1} \cdot$ Alexandros Delimpaltas $^{1}$. \\ Efterpi Demiri $^{1} \cdot$ Mimis Cohen $^{3}$
}

Published online: 1 May 2020

(C) Springer Science+Business Media, LLC, part of Springer Nature and International Society of Aesthetic Plastic Surgery 2020

\section{Correction to: Aesth Plast Surg https://doi.org/10.1007/s00266-020-01679-1}

Georgia-Alexandra Spyropoulou's name appeared incorrectly in the original publication of this article. It appears correctly here.
Publisher's Note Springer Nature remains neutral with regard to jurisdictional claims in published maps and institutional affiliations.

The original article can be found online at https://doi.org/10.1007/ s00266-020-01679-1.

Georgia Alexandra Spyropoulou

gspyropoulou@ hotmail.com

1 Clinic of Plastic and Reconstructive Surgery, Aristotle University of Thessaloniki, Papageorgiou Hospital, Thessaloniki, Greece

2 Hunfalvy Bilingual Secondary Vocational School, 1011 BudapestPonty utca 3, Hungary

3 Division of Plastic, Reconstructive and Cosmetic Surgery, Craniofacial Center, University of Illinois, Chicago, IL, USA 